This item was submitted to Loughborough's Research Repository by the author.

Items in Figshare are protected by copyright, with all rights reserved, unless otherwise indicated.

\title{
Facilitated post-model coding in Discrete Event Simulation (DES): a case study in Healthcare
}

PLEASE CITE THE PUBLISHED VERSION

https://doi.org/10.1016/j.ejor.2017.10.047

PUBLISHER

Elsevier

VERSION

AM (Accepted Manuscript)

PUBLISHER STATEMENT

This paper was accepted for publication in the journal European Journal of Operational Research and the definitive published version is available at https://doi.org/10.1016/j.ejor.2017.10.047

LICENCE

CC BY-NC-ND 4.0

\section{REPOSITORY RECORD}

Kotiadis, Katherine, and Antuela Tako. 2019. "Facilitated Post-model Coding in Discrete Event Simulation (DES): A Case Study in Healthcare". figshare. https://hdl.handle.net/2134/27336. 


\title{
Facilitated post-model coding in Discrete Event Simulation (DES): A case study in Healthcare
}

\author{
Kotiadis $\mathrm{K}^{1}$ and Tako $\mathrm{AA}^{2}$ \\ ${ }^{1}$ Business School, Canterbury Christ Church University, Canterbury, Kent, UK, \\ CT1 1QU
${ }^{2}$ School of Business and Economics, Loughborough University, Leicestershire, LE11 3TU, UK.

Corresponding Author: K Kotiadis (email: Kathy.Kotiadis@canterbury.ac.uk or Kathy.Kotiadis@gmail.com)

\begin{abstract}
Research on facilitated discrete event simulation (DES) is gathering pace but there is still a need to put forward real examples to explain the process to newcomers. This paper is part of a line of research on the methodology of facilitated DES. In this paper we explain in more detail the facilitation process and the tools used to support the experimentation and implementation stages in a DES study involving workshops with a group of stakeholders, after an initial simulation model has been coded on the computer. A real case study is used to describe the process followed and the interactions at the workshops. Extracts from the transcripts are also included, with the view to providing evidence of the stakeholders' involvement and their mood during the workshops. We conclude with a discussion on the process and tools used to support the facilitation process. Future research directions are also put forward.
\end{abstract}

Keywords: Problem structuring, Facilitated modelling, Experimentation, Implementation, OR in Health Services.

\section{Introduction}

Facilitated discrete event simulation (DES) offers an alternative mode of engagement compared to the traditional expert mode of undertaking DES, where the focus is on an individual client rather than on a group of stakeholders. The expert mode encourages the operational researcher(s) to use the simulation model to undertake an objective analysis of the client's problem and then recommend optimal or quasi-optimal solutions (Franco and Montibeller 2010). In facilitated DES the aim is for the operational researcher(s) to use the model in a workshop(s) with several stakeholders to enable a subjective analysis, where the solutions are viewed as feasible and desirable, whilst taking into 
account environmental constraints. This subjective analysis allows for multiple views to be expressed, with the group eventually converging to one common view.

Facilitated DES research is gaining momentum and could have a considerable impact on DES applied to service-based industries such as healthcare where there is a recognised need for multiple and diverse stakeholder involvement (Wilson, 1981; Lowery, 1994; Jun et al, 1999; Fone et al, 2003; Gunal and Pidd, 2005; Eldabi et al, 2007; Pessôa et al, 2015; Baril et al, 2016). Indeed recent evidence suggests that simulation in healthcare is perceived differently and specifically considered more difficult compared to other sectors (Tako and Robinson 2015). Quite often this is due to the complex nature of healthcare systems which involve multiple stakeholders with distributed power and knowledge.

More research is needed in facilitated DES for it to become a common mode of practice in healthcare simulation. Existing research in facilitated DES considers: the process of engaging a group of stakeholders in workshops (Robinson et al 2012; Robinson et al 2014), the framework that could be deployed (Tako and Kotiadis 2015), the processes and tools for pre-model development stages (conceptual modelling) (Kotiadis et al 2014) and making the model-development (coding) phase more facilitated (Proudlove et al 2017). An area of facilitated DES research that is not sufficiently addressed is the process followed after the development of an initial simulation model on the computer. In this paper we refer to these stages collectively as the post-model coding stages for the sake of clarity. Similarly, we also refer to the stages prior to the development of a computer simulation model as the pre-model coding stages. This does not mean that modelling does not take place in the pre- or postmodel coding stages. Indeed in pre-model coding, modelling can involve for example the use of Soft Systems Methology tools to conceptualise the system, whereas some model coding continues to take place in post-model coding, due to the iterative nature of the modelling process.

Robinson et al (2014) suggest that future research should describe the process that a facilitator follows in a workshop using real examples of facilitated DES. This paper focuses on the process followed as part of the experimentation and implementation stages of the PartiSim framework (Tako and Kotiadis 2015). We use a real case study in health care to describe the process and interactions between the group of stakeholders and analysts that took place in two facilitated workshops. The interactions in the former workshop are aimed at exploring the solution space (experimentation stage) and in the latter workshop at narrowing the solution space to feasible and desirable action to be taken by the stakeholders (implementation stage). We describe the suggested workshop activities that could be used to inform other studies. The work presented in this paper contributes primarily towards the practice of facilitated DES by describing the activities undertaken. We provide evidence using extracts from workshop transcripts. Secondly, we introduce the use of tools to support a group (stakeholders 
and analysts) to achieve the aims of the facilitated DES workshops following the development of an initial simulation model. Pre-model coding tools that aid the facilitation process during the pre-model coding stages (conceptual modelling) have been already reported in Kotiadis et al (2014).

The paper is structured as follows. The following section explores the existing facilitated DES literature and focusses more specifically on facilitation in the experimentation and implementation stages of DES. The process followed is then demonstrated in a real life case study, describing also the tools (new and existing) used to support this process. A discussion follows with reflections on the process and tools used to support facilitated post-model coding. This section also puts forward practical considerations and future research directions.

\section{Background}

A little over 15 years ago Taket (2002) noted that facilitation was emerging as a term and listed a number of existing books (e.g. Taket and White (2000)) and articles (e.g. Huxham (1991); Phillips and Phillips (1993); White and Taket (1994)), none of which included facilitated discrete event simulation, although Group Model Building had already established itself (Vennix 1999). The term facilitation has only been adopted in the last few years by the DES community (van der Zee 2007; 2011; Tako et al 2010; Barjis 2011; Tako and Kotiadis 2012a, b, 2015; Kotiadis et al 2014; Robinson et al 2014) but nevertheless ahead of other hard OR approaches (such as linear programming, combinatorial optimisation, etc.) that appear to have not yet explored the opportunities that facilitation has to offer.

Franco and Montibeller (2010) describe the differences in expert and facilitated mode for OR consultancy. In expert mode the stage of evaluating options, which would follow the development of a model, is described as 'a model is solved by the operational researcher, and optimal solutions for the problem are found' ( $p$ 490). In contrast the same stage in the facilitated mode is described as interactively evaluating options with the management team with the consequences of each option being assessed. Indeed all the stages they compare have a different focus under the different modes.

In the analysis that follows we classify modelling activities into three broad categories: 1) pre-model coding to include understanding the problem and conceptual modelling, 2) model coding, including data collection and building the model code onto the computer and 3) post-model coding to include experimentation with and/or implementation of the model.

\subsection{Facilitated DES for the experimentation and implementation stage}

The post-model coding stages in Facilitated DES generally have a different focus to the expert mode. Similarly to OR consultancy in general, in DES the focus for the facilitated mode is on the 
communication and exchange with the client group and the focus of the expert mode is on the model and its findings. In expert mode DES, the stage of experimentation refers to two clusters of activity. The first is about obtaining accurate results on the performance of the model using statistics and the second is about searching the solutions space again utilising statistics (Robinson 2014). In expert mode, implementation is about implementing the findings of the simulation model. This stage has some overlap in its focus with the facilitated mode of simulation as it does require communication with the client(s) but does not support the client beyond reporting the simulation output ususally in the form of a report or presentation.

Facilitated DES could learn a great deal from Group Model Building (GMB) given the level of maturity it has reached as a field (Vennix 1996). Indeed some facilitated DES approaches have been influenced to some extent by GMB such as the use of workshops (Tako and Kotiadis 2015; Robinson et al 2014), the idea of following a structured process within a workshop (Kotiadis et al, 2014) with supported guidance for activities within a workshop (known as scripts in GMB) (Kotiadis and Tako 2010). Looking more specifically at post-model coding stages in GMB, the process followed varies, however the common elements reported in the literature include model testing and strategic policy development (Vennix 1999, Richardson and Andersen 1997, Rouwette, Vennix and Thijssen; 2000), due to the different perspectives taken in system dynamics (the modelling tool used in GMB) focusing primarily on the feedback effects. The models are based on stocks and flow structures which are expressed into partially differentiated equations that represent the relationships between the variables. In DES the models are object-oriented, representing the entities and/or people flowing through the system. Even though the aim of the activities undertaken in GMB and facilitated post-model coding DES is the same, the type of activities and discussions that take place during experimentation and implementation is different. This is driven mainly by differences in model representation and modelling philosophy taken (Tako and Robinson, 2009). Hence considerable independent facilitated DES research is needed to guide simulation modellers in the process and to make the 'art more of a science'.

We now look at existing facilitated DES studies and consider the steps followed focusing especially on the post-model coding stages and identify the frameworks developed, if any.

Adamides and Karacapilides (2006) put forward the framework of the Group Model Building by Selection and Argumentation (G-MoBSA) methodology which appears to be largely focussed on premodel coding facilitation and the model coding, which is not to say that post-model coding is not supported. The objective for this approach is to reach an accommodated stakeholder view of the process (the existing or future) process in a specific modelling formalism. As this approach can support 
remote and asynchronous participation using an ICT infrastructure it is a very different interpretation of facilitation from the studies we consider next.

Den Hengst et al (2007) reports on a collaborative simulation study for a Dutch airline carrier, that combines group support with simulation modelling. They follow a facilitated modelling approach with five basic activities: conceptualisation, model building, development of alternative models, selection of preferred solution and implement solution. Six facilitated meetings with different members of the stakeholder team are held. Those attending these meetings are invited based on the level of decisions to be taken at the different stages/meetings. As a result of the study a large and detailed model was developed outside the workshops, which was not possible to run live to discuss in the workshops with the stakeholders. Instead a smaller version of the model was used in the workshops. Post model coding workshops involved only the management team and concentrated on validating the model, considering alternatives and choosing a direction for the future.

Robinson et al. (2014) provides empirical evidence of carrying out facilitated modelling with a group of healthcare professionals at an outpatient's eye clinic, as part of a lean improvement workshop, hence called SimLean. The lean workshops were held in two whole day sessions (Monday and Wednesday), with the DES model being developed in the day between the two workshops. In day one the participants developed process maps using sticky notes and identified estimates for main variables in the system. A simple model was built in between workshops, which was then presented to the participants in the second day of the workshop and used to discuss lean improvements. The authors put forward the steps followed during the process but did not report using tools to support the facilitation process in the workshop.

Tako and Kotiadis (2015) propose a framework for healthcare, called PartiSim, which stands for participative (discrete event) simulation. The framework is designed to support the modellers' interaction with a group of stakeholders throughout the whole DES study lifecycle. It includes a number of prescribed activities and corresponding stakeholder-oriented deliverables (outputs) for each stage of the simulation study, which enable participative and facilitated DES modelling to take place. PartiSim is formed of six key stages and five sub-stages. The key stages include: 1 . Initiate simulation study; 2. Define Problem; 3. Define conceptual model; 4. Model Coding; 5. Experiment with model; 6. Implement Findings. The sub-stages support the main stages, either to prepare for the workshop-based stages or to tidy up outputs developed in workshops and confirm these with the stakeholders. Model coding, a middle key stage in PartiSim, is not undertaken in a facilitated mode and that is acceptable practice in facilitated DES (Robinson et al 2014). The least explored aspect of PartiSim are the post-model coding stages, which include experimentation, i.e. searching the solution 
space, and implementation, i.e. establishing action to be taken. These are explained in more detail in the case study part (section 3) of this paper.

We now broadly compare the studies above to each other, to identify any common ground. If we start by comparing PartiSim (Tako and Kotiadis, 2015) with SimLean (Robinson et al 2014), we immediately note that PartiSim workshops are shorter in time (e.g. aimed at two hours long) and more spread out (e.g. weeks apart) (Kotiadis et al 2014) whereas in an example of SimLean (Robinson et al 2014) it is described as two full days that encompasses the pre-model and post-model coding stages, respectively. If we compare PartiSim's post-model coding with an example outside of healthcare such as den Hengst's et al (2007), we note that the latter process is described as dedicating four out of the six key stages to post-model coding. This is twice as many key post-model coding stages as PartiSim. These differences will inevitably have an effect on facilitation and on the design of the workshop activities which is why a greater number of studies across different domains needs to be reported in the literature. We will continue these comparisons in our discussion section.

We next review the use of tools to support post-model coding facilitation in DES.

\subsection{Tools for Facilitated Modelling}

Robinson et al (2014) and Barjis (2011) identify the need for pre-model coding tools to assist the process of facilitation. Similarly, den Hengst et al (2007) suggest the need for developing aids and tools that can support the facilitation process and stakeholder engagement in the workshops. Kotiadis et al (2014) have put forward tools that aid the pre-model coding stages, which form conceptual modelling. These tools are not suitable for post-model coding because the outputs differ between these stages. PartiSim tools have been designed to fit the outputs of its intended stage (more details follow in section 3 below). Hence we will distinguish PartiSim tools from general facilitation tools used to record and enable general debate that could be used in theory at any stage. For example, Group Support Systems (GSS) used by den Hengst et al (2007) offer anonymity, parallel input and group memory. GSS are said to support five different patterns of collaboration: divergence (e.g. brainstorming), convergence (clarify and reduce), evaluation, organization, and building consensus (Briggs et al, 2006). For more information on GSS we refer readers to look at the following (Nunamaker et al, 1991; 1997; Tyran et al, 1992; Fjermestad and Hiltz, 1998-1999; Davison and Briggs, 2000; Briggs et al, 2003; Adamides and Karacapilides 2006).

\subsection{Review summary}

Reflecting on the literature reviewed we make the following key observations. Unlike the pre-model coding stages (Kotiadis et al, 2014), the PartiSim stages after an initial model is developed and then 
used to inform discussions (what we call post-model coding stages) have not been explained in detail so it is not clear how they compare to the stages that other facilitated studies have put forward. Furthermore, no tools have been put forward that can specifically support the post-model coding stage, unlike the pre-model coding stages that benefit from tools (Kotiadis et al 2014). Barjis (2011) makes the point that facilitated DES would benefit from the development of tools to support the process. We next explain PartiSim's post-model coding stages in practice using a real example in healthcare and itroduce the tools that we found useful in supporting the process.

\section{Overview of the PartiSim experimentation and implementation stages}

PartiSim's (Tako and Kotiadis 2015) post-model coding stages include two main workshops: the experimentation (stage 5) and implementation (stage 6) and the relevant pre-/post- workshop substages (4.a, 5.a and 6.a). Earlier stages (stage 1 to stage 4) are detailed in Tako and Kotiadis (2015). Table 1 below provides a list of the post-model coding stages and the specific activities taking place, the suggested tools used (these are paper based and freely available) with their manuals which support the process of using the tools to reach to the prescribed dedicated outputs for each stage. Some scripts are also provided, aimed mainly at the facilitator. These are different from the tools or manuals in that they include advice to support the facilitation process for activities that do not require any specific tools to be used.

Table 1 The post-model coding stages in PartiSim (Adapted from Tako and Kotiadis 2015)

\begin{tabular}{|c|c|c|c|}
\hline Stage \& purpose & Activities $^{1}$ & Tools & Outputs $^{2}$ \\
\hline $\begin{array}{l}\text { 4.a Pre-workshop } 3 \text { sub- } \\
\text { stage } \\
\text { Purpose: } \\
\text { Preparations for Workshop } 3\end{array}$ & 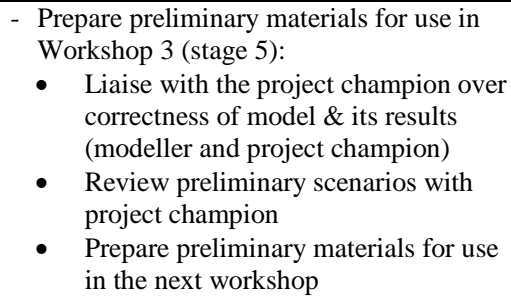 & & $\begin{array}{l}\text { Model results } \\
\text { Model validation and } \\
\text { verification } \\
\text { Preliminary future } \\
\text { scenarios }\end{array}$ \\
\hline $\begin{array}{l}\text { 5. Experimentation stage } \\
\text { (Workshop 3) } \\
\text { Purpose: } \\
\begin{array}{l}\text { Define alternative scenarios } \\
\text { to experiment with model }\end{array}\end{array}$ & $\begin{array}{l}\text { Stakeholders are invited to: } \\
\text { - Validate the simulation model \& its } \\
\text { results } \\
\text { - Rate performance measures (linked to } \\
\text { model results) } \\
\text { - Debate desirable and feasible scenarios }\end{array}$ & $\begin{array}{l}\text { Model validation tool } \\
\text { Rating the Performance } \\
\text { Measures tool (or VISA) } \\
\text { with manual } \\
\text { Debating the Alternative } \\
\text { Scenarios tool with manual }\end{array}$ & $\begin{array}{l}\text { Model validation and } \\
\text { verification } \\
\text { Alternative future scenarios }\end{array}$ \\
\hline $\begin{array}{l}\text { 5.a Post-workshop 3/ Pre- } \\
\text { workshop } 4 \text { sub-stage } \\
\text { Purpose: } \\
\text { Refine alternative scenarios \& } \\
\text { prepare for Workshop } 4\end{array}$ & $\begin{array}{l}\text { Modelling team: } \\
\text { - Tweak or correct simulation model } \\
\text { - Implement additional scenarios suggested } \\
\text { (based on stakeholder feedback from } \\
\text { Workshop 3.) } \\
\text { - Liaise with the stakeholder team over } \\
\text { correctness of model results } \\
\text { - Prepare preliminary materials for use in } \\
\text { Workshop } 4\end{array}$ & & $\begin{array}{l}\text { New alternative future } \\
\text { scenarios } \\
\text { Revised simulation model } \\
\text { Revised model results }\end{array}$ \\
\hline $\begin{array}{l}\text { 6. Implementation stage } \\
\text { (Workshop 4) } \\
\text { Purpose: } \\
\text { Define an implementation }\end{array}$ & $\begin{array}{l}\text { Stakeholders are invited to: } \\
\text { - Review learning \& changes implemented } \\
\text { - Risk analysis and feasibility of change } \\
\text { - Agree action trail }\end{array}$ & $\begin{array}{l}\begin{array}{l}\text { Script for Identifying } \\
\text { changes in the system }\end{array} \\
\text { Feasibility and Risks Scale } \\
\text { tool with manual }\end{array}$ & $\begin{array}{l}\text { Agreeable and feasible } \\
\text { scenario(s) to be taken } \\
\text { forward }\end{array}$ \\
\hline
\end{tabular}




\begin{tabular}{|l|l|l|l|}
\hline plan & & $\begin{array}{l}\text { Action plan with } \\
\text { Barriers to Change tool } \\
\text { with manual } \\
\text { deliverables (including due } \\
\text { date and person } \\
\text { responsible) }\end{array}$ \\
& $\begin{array}{l}\text { Action and Communication } \\
\text { Plan tool with mannual }\end{array}$ & \\
\hline
\end{tabular}

${ }^{1}$ Two types of activities: modelling activities and workshop activities. Workshop activities are shown in italics.

${ }^{2}$ Outputs represent stakeholder-oriented deliverables

\subsection{Stage 5: Experimenting with the model}

The aim of this stage is to define alternative scenarios and relevant changes to experiment with the simulation model, not necessarily choosing the most preferred scenario. It takes place in a workshop setting. The process followed during this workshop is closer to the interactive experimentation approach in DES (Robinson 2004), where the aim is to develop a general understanding of the model and its key problem areas. The main activities undertaken in the experimentation workshop are next described, referring to the dedicated tools and facilitation guidance.

Validate the simulation model and its results. In this workshop stakeholders initially explore the computer model to determine if it is valid for its use. A live demonstration of the model structure is a means of generating confidence in the model and its results (Barber 1977). Stakeholders and modellers can use the Model Validation Tool (Table 1), a paper based tool, to reflect on the model and record any changes needed to improve its validity. The responses on the tool form can be collated by the modelling team. If the model is deemed sufficiently valid the workshop can proceed to the next activity.

Rate performance measures. The stakeholders revisit the performance measures identified in a previous workshop (part of conceptual modelling) and rate them according to their importance using a paper based tool or the VISA software (www.visadecisions.com). The process followed to use this tool is captured in a manual (Kotiadis and Tako 2010), which operates similarly to GMB scripts (Andersen and Richardson 1997). This activity contributes to the next activity aimed at helping the stakeholders to reduce the solution space, i.e. identify scenarios that achieve improvement of performance measures.

Debate desirable and feasible scenarios. The stakeholders are shown the preliminary future scenarios which are used to encourage debate. These are intended to help them determine the feasible and desirable solution space and define relevant alternative scenarios (Table 1 column: Outputs) within it. The modelling team prepare these preliminary scenarios prior to the workshop (sub-stage 4.a). After workshop 3 (stage 5.a), the modelling team undertakes further experimentation in order to obtain statistically significant results (Robinson 2004). A report outlining the model results and findings is subsequently prepared and sent to the stakeholders for reflection (stage 5.a). 


\subsection{Stage 6 Implementation stage}

The final PartiSim stage, implement findings (workshop 6), is undertaken in a workshop setting, which is based on the learning achieved so far during the simulation study. Stakeholders are invited to express their views and to debate their plans for the future. The workshop aims to move the stakeholders away from the model and its findings towards gaining an understanding of the present and future implications of each scenario. Feasible and desirable changes can be identified, in order to enable action to be taken in the real system. Developing change plans, planning for training and exploring the impact of system implementation can develop favourable attitudes toward the model and the study (Hoover and Perry 1990).The main workshop activities are next described.

Review learning \& changes implemented. A facilitator may summarise the findings of the most promising scenarios explored in the computer simulation model which will have been described in the report sent to the stakeholders prior to the workshop. An important aspect of the implementation workshop is to create awareness of the learning generated throughout the study as this is one of the main benefits of DES studies (Robinson 2004). The modellers/ facilitator may need to intervene in creating awareness of the learning achieved (Nisbett and Wilson 1977; Robinson 2004; Rouwette et al. 2009), which can in turn help develop actions to address their problematic situation. A script is available with a number of leading questions to support the facilitator undertaking this activity. One example of a question in the script is 'Have any changes been (already) introduced to your system?'. At the end of this activity the facilitator and modelling team will have captured some of the learning but also captured action that has already taken place during the study. This could mean that the implementation of a scenario has already taken place in part or fully. This is the first activity in the workshop given that subsequent activities such as considering the feasibility of a change or taking action might not be necessary.

Risk analysis and feasibility of change. Next, the risks and feasibility of each change in a potential scenario are discussed in order to agree on a preferred scenario(s) to be pursued. Roberts-Gray (1985) suggests that supporting the stakeholder team in overcoming barriers to change is a key factor to enabling the success of implementation plans. Barriers are positive and negative elements, as called in scenario planning (Schoemaker 1995), which include also psychological perceptions (Ajzen 1991) that may hinder the stakeholders from taking action. Ajzen (1991) maintains that communication that attacks believed constraints can produce changes in attitude towards a behaviour. Hence debate and discussion is considered important to challenge attitudes and perceptions towards change. To add to this line of argument, for debate to lead to implementation, Schultz et al. (1987) explain that debate and the unveiling of the diversity of opinions is likely to change future management strategy because discussions help to change management's own values, personal beliefs, and attitudes. Debate and 
discussion is important to challenge attitudes and perceptions towards a change, and communication and involvement can provide further support for change. Also at this stage clients may agree with a decision to be made, i.e. to increase the number of appointments provided to improve efficiency, but this requires consideration of aspects related to it that may have not been even included in the modelled such as bed availability, senior managements willingness to invest, staff willingness to make the change, etc. This acivity aims to surface this tacit knowledge so that an action to tackle this can be assigned in the following activity. During this activity the facilitator might use a tool to rate the feasibility of each scenario. Feasibility and Risk Scales tool and its manual (table 1) offers a structured process to explore scenarios in sequence starting with the preferred one.

Agree action trail. Having agreed on a promising scenario (or scenarios), further analysis is undertaken to explore any additional changes needed (going again beyond the changes to the inputs of the model) for the implementation of the scenario and to challenge any remaining psychological and physical barriers. This approach also explores the expected benefits of any additional changes. The Barries to change tool and manual (Table1) is used for this activity. If the stakeholder group are sufficiently confident in the scenario (Table 1 column: Outputs), an action plan is next determined, with clear actions, including what, by when and who is responsible (Table 1 column: Outputs). An action and communication plan tool with its manual can assist the facilitator in this process. The development of this tool has been influenced by SSM's stage of determining action (Checkland 1999) to be taken where it is common practice to record the action and the responsibility for it. The end of the workshop marks the end of the intervention process, however the implementation of change(s) continues beyond Workshop 4.

We next explain the activities described above as they were followed in the post model coding stages in an intervention of an obesity care study. Extracts form stakeholder-led discussions that took place are also provided.

\section{Case Study}

\subsection{The context}

The case study is about a UK's National Health Service centre offering patients with morbid obesity lifestyle, pharmacotherapy and surgery treatment options. For confidentiality reasons we will not refer to the centre by its name. The study was commissioned to the modelling team by a group of stakeholders based at the aforementioned centre on a pro-bono basis with the understanding that the group of stakeholders participating would be involved throughout the modelling process. At the time of this research (early 2010) the centre was just about meeting the demand. However, in the long 
term, they recognised that they would be running the risk of building long waiting lists, with patients experiencing long waits and risk breaching government directives, such as the 18-week target (patient maximum wait time from referral to first treatment) set by the Department of Health in the UK (Department of Health, 2004).

A stakeholder group of around 12 had accepted the invitation to participate in the workshops. A key stakeholder took on the role of project champion without encouragement from the modelling team and the individual involved already led a number of meetings and other research activities for that group. The project champion, who was a physisian facilitated the exchange of information/understanding between stakeholders and researchers especially during the pre-workshop stages of 4.a and 5.a (Table 1). However keeping track of the stakeholders in these particular workshops was not straightforward as they took place on a hospital site and some people arrived late or left early. For the sake of prudency we can say that between six and twelve people were present at any moment during these workshops. The workshops were organised in two hour slots each. The stakeholder group consisted of a wide representation of different parts of the obesity care system, including healthcare professionals (surgeons, doctors and nurses) of different seniority from a range of specialties such as general surgery, chemical biochemistry, anaesthetics and endocrinology as well as members of the senior management team. The modelling team involved three analysts (two of them were the authors, who have extensive experience of DES modelling using off the shelf simulation software), who took on different roles, that of the facilitator, modeller, recorder (note keeper) etc. during the period of the project.

It should be noted that in our interactions with the stakeholders as part of the pre-model coding stages of the study (for more details please refer to Kotiadis et al 2013), it was agreed that the aim of the study was to identify the impact that an increase in resources (surgeons and physicians) and/or a reduction of patient referrals (lower referral rates) into the service, would have on the 18-week target. More specifically, the finally agreed simulation study objectives were:

Objective 1: To explore reducing the waiting list for the surgical clinics, pharmacotherapy clinic and patient education by incrementally increasing the number of surgeons and physicians to a maximum of three and two respectively as well as reducing first time referrals.

Objective 2: To explore reducing the percentage of patients that breach the 18-week target by incrementally increasing the number of surgeons and physicians to a maximum of three and two respectively. 
Objective 3: To explore reducing the percentage of patients that breach the 18-week target by managing demand through a reduction in patient referral rates into the service.

The simulation model was built in Simul8 (www.simul8.com) because it was readily available to the modelling team and the team were familiar with using it. A screenshot of the base simulation model is provided in Figure 1. Model coding took approximately two to three weeks but the model coding period spanned a longer time frame because modifications and iterations took place as a result of feedback received from the stakeholders and also due to other factors such as public holidays and getting hold of data.

The readers should note that although we describe the process of experimentation and implementation we do not provide a lot of detail of the solution space as our aim is to describe the workshop experience and explain the tools used to support facilitation. Instead we provide some snippets of the workshop transcripts to provide readers with a sense of the interactions. However further information on the actual scenarios and the associated findings can be found in Tako et al (2014). We next describe the post-model coding process followed.

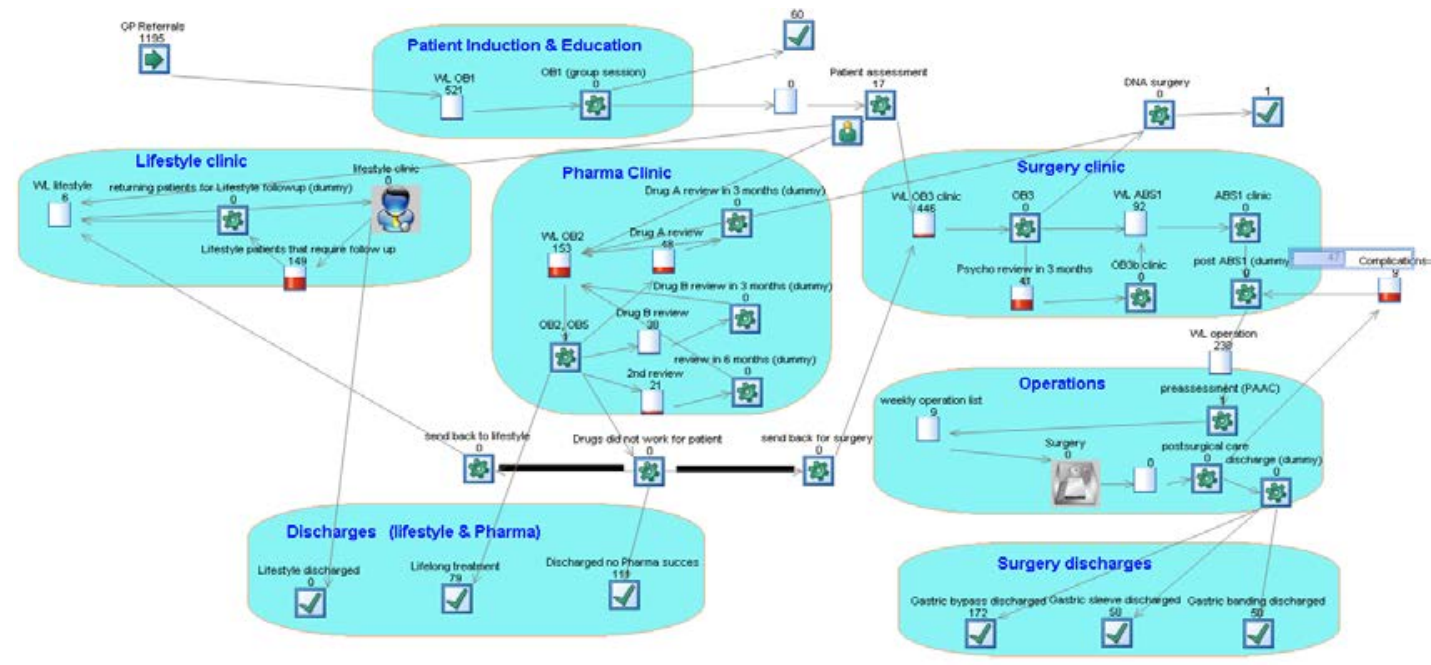

Figure 1: Screenshot of the Simul8 model of the current situation of the obesity system

\subsection{Sub-stage 4.a Pre-workshop 3}

After a working (initial) model was developed, and before proceeding to the experimentation workshop (Workshop 3 in PartiSim), the modelling team held a meeting with the project champion with the view to pre-validating the model. Furthermore, some preliminary scenarios for experimentation were also discussed with the project champion. These scenarios and the results were prepared before the workshop and aimed to provide the workshop participants a good starting point for exploring the solution space rather than simply turning up with a base model (Figure 1). As part of 
the preparations for workshop 3 the modelling team prepared materials (e.g. slides and handouts) and practiced the process to ensure good communication on the day.

\subsection{Stage 5: Experiment with model (Workshop 3)}

This workshop was organised around three objectives: to validate the simulation model and its results, rate the performance measures and to debate the desirable and feasible solution space.

\section{Validating the simulation model and its results}

The workshop started with a structured 'walk through' of the computer model of the current situation. The participants had met a few weeks earlier to participate in the relvant workshop for developing the conceptual model. This was the first encounter with the simulation model for the workshop participants, except for the project champion. Hence it was important to dedicate a good fraction of workshop time to this activity (approx. 45 minutes). During this time, the stakeholders were given the opportunity to absorb the new information, to familiarize themselves with the model and its animation, how the logic works, its results, and ask questions. Explaining the model in such detail has been identified as important in collaborative simulation where models are expected to be understood by the participants and run in seconds (den Hengst et al 2007). The model in this case study could be run in a few seconds.

The facilitator encouraged participants to engage by posing various questions on whether their system has been adequately represented in the model. Many of the participants asked questions in return and some heated discussions took place about the inputs into the model. The project champion played a crucial role in this stage to maintain participants' confidence in the model. He acted as an advocate of the simulation model by explaining the assumptions made to the rest of the participants, in language they were more familiar with. He explained where the data came from and why the results of the base model were realistic. For example:

"... what they (the modellers) have done is they've combined that number, that 70 and that 58, so that's for the waiting list for surgery, so this is looking at a combination." [Project champion]

Some modifications to the model were suggested during the discussion, such as adding surgical complications into the model. The modifications, which were captured with the model validation tool (Table 1), did not invalidate the model, but extended its detail. The modelling team considered this as a good sign firstly because it meant the stakeholders understood the model well enough to ask for extensions and secondly because the ownership of the model was reverting back to the group who were in fact the designers of the conceptual model (Kotiadis et al 2014). For the purpose of keeping to the focus of the workshop, given the limited time available, the modelling team promised to make 
these changes after the workshop and to re-circulate the results. Further proof that the modifications to the model did not diminish the stakeholders' perception about the model can be found in the following extracts that show their reaction to the outputs of the base model (current situation):

Project champion: "So well done with the model so far."

Project champion: "now for the purposes of the model, the model is fine"

Project champion: "We're all happy with the assumptions that are actually going in and out now, right?

Other Stakeholder: "Yep"

It was therefore deemed by the modelling team and the stakeholders that the workshop could continue beyond the initial validation with the understanding that the complete findings would be circulated following the workshop. The next activity focused on reaching consensus among the stakeholders on the importance they attached as a group to each performance indicator.

\section{Rating the performance measures}

Performance measures or indicators, are in fact some of the key model outputs. The aim was for the stakeholders to focus on the most important measures to ultimately narrow the solution space. These had been already identified by the stakeholders during pre-model coding (Kotiadis et al 2014), but had not been rated against each other to filter out the ones that were less important to the stakeholders. In this activity the participants were guided through a process to identify and negotiate the importance attached to each of the performance measures.

The approach taken to complete this activity is influenced by multi-criteria decision analysis (MCDA) (Belton and Stewart 2002) and can alternatively utilise existing MCDA computer tools such as VISA software (http://www.visadecisions.com). The activity was guided by the Rating the Performance Measures Tool and its manual. This consists of a value tree representing model results (performance measures) and the weight in terms of importance attached to each one by the stakeholders (Figure 2) built using the VISA software. The value tree was set up prior to the workshop using the performance measures that were identified in the pre-model coding workshops and during model coding. It should be noted that the modelling team had only recently started to learn and use VISA and to avoid any unexpected technical hitches and subsequent delays, prepared printouts of VISA outputs in advance. Nevertheless, the VISA software has the potential to be used live, if the modelling team is familiar with using it. The benefit of using VISA live in the workshop lies in that the results of different scenarios, can be connected with the agreed value tree in order to evaluate each scenario and to identify the most desirable and feasible scenario/(s). This is because the VISA software is compatible with the simulation software used (www.simul8.com) to develop the DES model. It is also entirely possible for 
the approach to rate the performance measures using the paper-based tool (Table 1), without the VISA software and/or anonymously, as explained in the PartiSim toolbox (Kotiadis and Tako 2010).

The facilitator asked the stakeholders to express their opinions about the importance of each performance measure, by weighing each one on a scale from zero to one hundred (Figure 2). During the validation part of the workshop, it had already become clear that the waiting lists were of high importance to all stakeholders, especially for the pharmacology and surgery clinics. The stakeholders on the whole agreed with the weights assigned prior to the workshop (Figure 2) so no changes were needed.

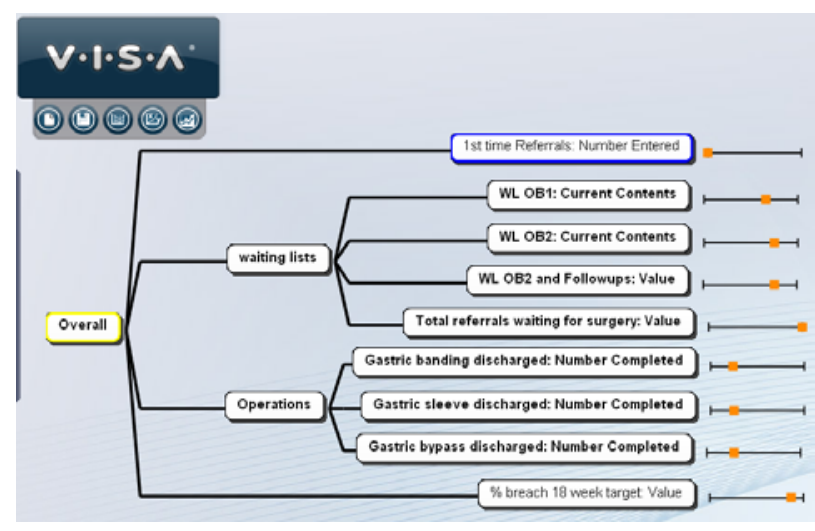

Figure 2: Value tree rating performance measures of the obesity system using VISA software

\section{Debating desirable and feasible scenarios}

In this part of the workshop, the attention turned to identifying the solution space by exploring a number of scenarios. This activity can be carried out using the Debate Alternative Scenarios Tool and the guidance in its manual (Table 1). As a starting point, nine scenarios (one base and eight preliminary future scenarios) were brought in at the workshop, based on the information available to the modelling team from the pre-model coding stages and after pre-validating the simulation model with the project champion (sub-stage 4.a). In hindsight, eight future scenarios were far too many and about half were immediately declared as irrelevant by the stakeholder group. The relevant scenarios were observed with great interest by the participants. They observed and discussed the visual display of the model with patients progressing through the pathway under the different scenarios.

Using the visual display in Simul8, where stakeholders could see the build-up of the waiting lists on the screen was a useful exercise that supported their understanding of the simulation model and initial scenarios. This helped the process of developing further future scenarios that were more relevant to the group of stakeholders. We had planned a separate brainstorming session to encourage stakeholders to suggest further scenarios that could be explored but this group were keen to suggest ideas while the scenarios were being presented. We did not modify the model to run new scenarios in 
the workshop because of the time required to make the changes and undertake the statistical elements of experimentation (multiple runs, warm up time, t-tests etc.).

The workshop ended by summarising the process and reinforcing the learning achieved. To aid this activity the facilitator had posed a number of open-ended questions during the workshop such as:

- Do you find the information you have received so far (results of the model) useful for decision making?

- Did you expect this result?

- Do you feel the results give you decision making power?

Some of the feedback at the end of the workshop included the following:

"You've given us all the information we needed, or I needed." [Stakeholder A]

"Yeah, I think it's going to help to better resource things and there's the timescales as well so we know at what point things might happen ..." [Stakeholder B]

"It's been extremely helpful for me to understand and what it's done is it's identified the scenarios, it's given support to the scenarios that we all thought intuitively was right, but actually to see the numbers come out is extremely valuable. So one of the scenarios that we discussed was scenario 3, and we now know that that would be an absolute catastrophe ... and we know scenario 4 and scenario 8 are within our sort of stride. Good." [Project champion]

"For us, or anyway for me, the problem is that we have 500 people waiting to come and see us, that means GPs will stop referring to us, so you'll have a natural decay in numbers of referrals, and if you have 449 people in ... it will effectively crash our administrative support ..." [Stakeholder C]

\subsection{Sub-stage 5.a (Post-workshop 3/ Pre-workshop 4)}

Following the workshop the model was updated in line with the stakeholders' requests and the new scenarios were run. The results were sent to the stakeholders and in response a new set of scenarios were requested by the stakeholders to further narrow the solution space into a feasible and desirable region. The project champion had also requested that some extra scenarios should explore the staggered implementation of resources. Once the solution space was sufficiently explored and narrowed down a report was produced in close collaboration with the project champion to ensure that the language used was clear. The stakeholders were sent the report prior to the final workshop, which they had previously agreed to attend as part of the process.

Apart from running the new scenarios and preparing the report (Table 1, Ouputs), the modelling team prepared for the next workshop, by designing a process to be followed, developed materials (e.g. slides, hand-outs) as well as the tools to be used to support the process. In addition, the modelling team ran a mock workshop amongst themselves in an attempt to improve the flow of activities and communication on the day. 


\subsection{Stage 6: Implementation of findings (Workshop 4)}

The final workshop of the study was dedicated to implementation. The workshop was organised with a slightly larger stakeholder group, approximately a dozen. Workshop 4 took place three months after the previous workshop, a comparatively longer time period than other PartiSim workshops, as it was felt paramount that all stakeholders, including the ones with decision-making power (the head of the surgical department) were able to attend. The workshop was structured around three key aspects: 1) review of learning and changes implemented (during the study), 2) risks analysis and feasibility of change, 3) agree action plan.

\section{Reviewing learning and changes implemented}

The workshop started with a reminder about the aims of the study, refreshing stakeholders' memory on what had been already accomplished. Robinson (2014) suggests that one of the main benefits of DES studies comes from the learning generated during the modelling process; yet the modellers/facilitator may need to intervene in creating awareness of the learning achieved. If the clients understand their problem situation and are given support in developing actions to address this, then they are more likely to implement the proposed solutions.

The facilitator referred briefly to the problem statement, the objectives, provided a visual display (a picture) of the simulation model and a table with the feasible and desirable scenarios, including the experimental factors (inputs) and the final model results. The briefing was only aimed as a warm-up to the workshop as the report compiled after workshop 3 had been circulated almost a month in advance and most stakeholders had already read it. Nevertheless, comments and extensive discussion took place because the report put forward the scenarios and the results but did not explain the behaviour of the performance measures. The stakeholders delved deep into the reasons for which these results were achieved. For example:

Stakeholder A: So how can this happen? I'm trying to understand. \{referring to a result\}

Stakeholder B: How does that work? I don't understand how that works \{referring to a result\}.

Project Champion: It works by the number of referrals, when you cut your referrals down. So if you outsource [number purposely deleted] but you keep your referrals coming in at the same rate, you don't change that.

Facilitator: I completely understand what you're saying. It's because of how you introduce the resources in the second scenario. If you introduce the physician earlier by the amount that we've introduced it, what the physician does is they push loads of patients forward.

Stakeholder A: Oh I see.

Churchman and Schainblatt $(1965$, p73) in their seminal paper emphasise the need for such an understanding to be reached 'For the proper communication to take place, the manager must 
understand what the scientist is trying to do, why he does it and what he does. Here the problem of implementation is the education of the manager. After a successful implementation, the manager himself becomes "more of a scientist".' Some of the stakeholder discussions about the results included assertions about their expectations and beliefs about the system. By getting the stakeholders to articulate these, the modelling team gauged the impact of the study and the learning gained by the participants. Some examples include:

[The numbers are] Slightly worse than we expected. [workshop participant]

I was very surprised that we actually, if we outsourced ... [number purposely deleted] patients, it actually makes it worse. I think that was a real solution. I thought actually taking ... [number purposely deleted] people out of the system would actually make the system better. Because it's ... my starting point has always been if we can clear the backlog and we can get the system in balance, that's the solution. [project champion]

Next, the stakeholders were prompted by the facilitator who used questions from a script (Identifying changes in the system, see Table 1) to report on any changes that might have already occurred in the system since the study started. From our communications with the stakeholders during the three month gap period between the two post-model coding workshops, we were made aware that additional surgical slots, equivalent to the addition of one surgeon, had been already introduced into the system following the first one. The model results demonstrated that this isolated implementation was found to be a poor decision because it led to bottlenecks when not combined with increases in other types of resources. The participants explained that it was a decision taken prior to the study and that the study would in fact influence the next decision they made. However, prior to the study we were told that there were no imminent changes to the resources. We relate this to the fact that learning is believed to occur gradually and the subjects themselves may not be aware of it happening as a result of changes in their system of beliefs and attitudes, used to make judgements (Ajzen, 1991). Their exposure to discussing their system could have meant that their understanding of their system had been building up as the study progressed. In hindsight, a more indirect way of identifying change of attitude would have been more appropriate, such as administering before and after questionnaires, recording stakeholders' plans or any additions in their knowledge/ learning as the study went on (Monks et al 2014). When discussing the impact of the change already made to the system and in light of the scenarios previously shown, stakeholders commented that this was a pretty much quick fix of the waiting list for surgery:

... we can now pretty much meet our steady state capacity, ... so that is enabling us to, based on monthly referrals, keep the backlog as it is rather than grow larger. But we still have obviously this big balloon after ... [clinic name deleted for confidentiality purposes] at the moment [meaning a large waiting list further up in the system]. [workshop participant]

Stakeholders recognised that there was a large waiting list further up in the pathway with patients waiting to be referred for surgery. The discussion that followed indicated that stakeholders 
understood that a more sustainable change needed to be implemented. This was clearly a learning point from the stakeholders' point of view during the review session, which provided evidence of the impact of such a decision (adding more surgeons) on the rest of the system.

\section{Analysing risks and feasibility of change}

This part of the workshop focussed on the most desirable scenario, and aimed to explore the factors that may hinder implementing the changes required. For example, earlier on in the workshop physical space was identified as an issue for implementation of any scenario:

Stakeholder A: I don't think this is working. I think this system internally, for us, having a third surgeon here, the third surgeon, the issue is not really physically, in terms of surgery, it's a case of space.

Stakeholder B: Beds and space.

Project Champion: We've assumed the space will just magically appear.

$<$ Laughter $>$

The aim here is to narrow the solution to ideally one scenario that could be implemented. Out of the scenarios explored the third scenario was the best performing scenario for most performance measures. This was also the most preferred scenario by all stakeholders. The facilitator asked the stakeholders to consider how this scenario could be put in place and the inhibiting factors were discussed. It is recognised that factors such as psychological perceptions may hinder the stakeholders from taking action (Ajzen 1991).

The facilitators used the Feasibility and risks scale Tool (figure 3 ) and its manual to identify the reasons for which this scenario was feasible and the reasons for which it was not feasible. The outcome was to weigh up its feasibility. The tool was designed prior to the workshop by the authors and the facilitator followed the process to construct it with the stakeholders. All stakeholders were encouraged to contribute to the discussion. The facilitator put forward two columns, one for reasons supporting the feasibility of the scenario and the other for reasons against it and recorded on a flipchart. The points made were listed and the scale was constructed by drawing a slopping line, dipping in this case on the not feasible side of the scale. The scenario was deemed to be not feasible in the short term because of the timescale of adding new resources in the real system. In the real life system, a delay of a few months in introducing the additional resources would not guarantee its results. As the admissions and waiting lists in the real system would be increasing it would take longer to reach equilibrium in the system, where key targets are not breached. As a result of this analysis, it was accepted that scenario 3 was not feasible mainly due to timing issues and a number of staggered scenarios that would ultimately lead to the same resources in the longer term were subsequently discussed. 


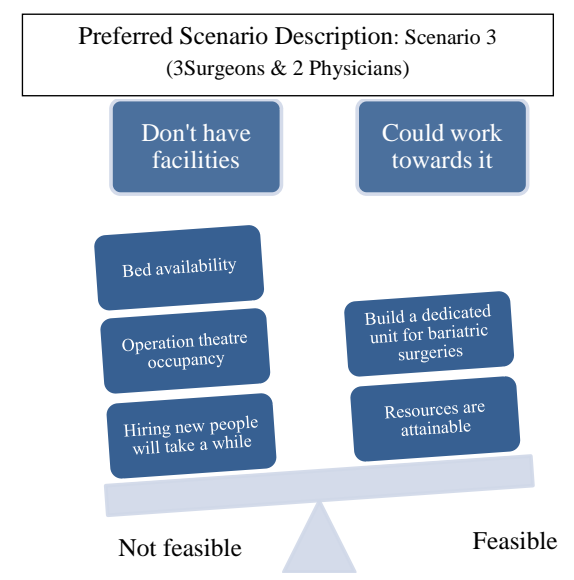

Figure 3: Example of using the feasibility and risk scale Tool to analyse a scenario

\section{Agreeing an action trail}

With a preferred scenario in mind the participants next concentrated on other indirect resourcing issues such as: improving referrals so they are appropriate; a dedicated unit space and the need for new surgical theatres; exploring outsourcing some part of their work elsewhere (to a different provider) and the financial impact of such a decision. The facilitator used the Barriers to Change tool to lead this activity. The stakeholders were invited to brainstorm and to record relevant actions for change in the form provided (Figure 4). They were then invited to share their ideas in the group and debate followed. The forms were theirs to keep and take forward in a move to hand over implementation and action back to the stakeholders. Next, the actions to be taken were recorded in a separate form (Action and Communications Plan Tool Table 1) with specific due dates and person accountable (Output of Table 1).

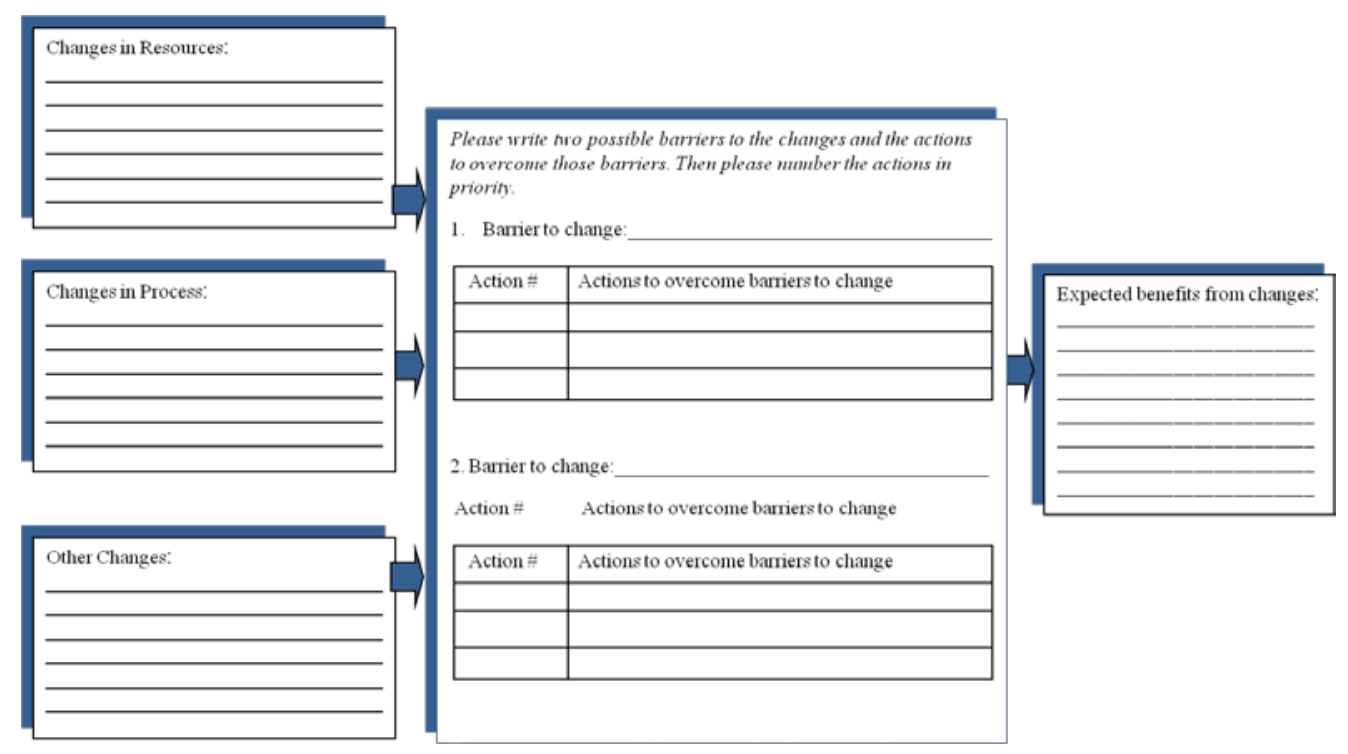

Figure 4 Recording actions in the Barriers to change Tool 
The workshop came to an end with the facilitator asking the participants to comment on the modelling approach and process as well as to fill in a brief survey. An extract from the conversation follows:

Project Champion: We've had good involvement.

Facilitator: It doesn't have to be good! [the extract follows from a series of positive comments so the facilitator is suggesting here that other less positive views can be expressed]

$<$ Laughter $>$

Stakeholder A: I agree with ... [name removed] in that I think we knew there was a problem, we knew where the problems were. What you've done is you've actually put it in black and white and we can actually see that it is clear, it's there, and that we need to do something about it. But I think what it's shown is every time we correct something, actually the problems work in [meaning the problem moves somewhere else].

Stakeholder B: It's the quantification and the clarification of the problem, quantified and clear. This I would say will increase, you can put numbers, it's quite an important thing to plan the resources... this process is proper process, this is the standard, proper process. You have a pathway and then you have a model and you validate the model in the workshop and see where the model ends up, so this process is a good process. There's a good process there....

As an immediate outcome of this study the Trust decided to add more surgeons to the service instead of adding physicians alone. Following the workshops, the Centre involved and the Primary Care Trust, engaged into discussions about changing the local eligibility criteria for bariatric surgery, which eventually led to a reduction in the number of referrals to the centre. A decision to build a new operating theatre was also made as the management team realised that additional capacity was needed in order to achieve aspired service levels and operation volumes.

\section{Discussion}

The discussion that follows will reflect on the facilitation process and tools for the stages of experimentation and implementation by contrasting: PartiSim with other facilitated DES approaches; Facilitated DES with other facilitative OR approaches; Facilitated DES with expert mode DES. We will then address future work.

\subsection{PartiSim experimentation and implementation stages with other facilitated DES approaches}

Considering only facilitated post-model coding DES, we now compare PartiSim to other facilitated DES approaches, such as SimLean, (used in a healthcare context) and to the collaborative modelling approach followed in den Hengst et al (2007) (carried out in a different context, the airline industry). This comparison focuses on the post model coding process and tools used, with the view to establishing occurring trends in the existing practice of facilitated DES. 
Following the development of the computer model (model coding), both SimLean and PartiSim have an activity dedicated to explaining the model to the workshop participants using the animation where stakeholders are encouraged to engage and ask questions. SimLean also has a phase focussed on validating the model and also seeking implementation with action being put forward at the end of their workshop. Considering the activities involved, we observe that PartiSim has a more structured sequence of activities, connected to specific outcomes and tools, whereas SimLean uses mainly the simulation model and some results, such as the distribution of queues to lead the discussion. SimLean also appears to entail a much more focussed discussion on the computer model, than PartiSim. It is difficult to attribute a reason for this but it could be related to the fact that SimLean requires that approach to demonstrate Lean Improvements. In PartiSim, after having validated the model and discussed the emerging queues, the stakeholders are coerced to think about alternative future scenarios. This is part of another activity where the scenarios and the relevant results are shown in a table format. Another aspect to consider is the fact that PartiSim can support the development of larger scale models compared to simple models in SimLean. However from our experience, a medium to a simple scale model is recommended to enable the stakeholders to digest the information in a workshop setting.

When comparing the post model coding process to den Hengst et al (2007) we again note similarities and differences to PartiSim's post-model coding approach. One key similarity is about handling the validity of the computer model. Den Hengst et al (2007) report that their model was not deemed to be valid and further extensions to the model were asked. This led to a second round of validation. In PartiSim (Kotiadis and Tako 2010) there is also an option to undertake a second experimentation workshop should the model be found to be invalid or not accepted by the stakeholders.

We will now consider a difference with den Hengst et al (2007), which relates to the importance placed on the pre-model coding stages. Den Hengst et al (2007) note some degree of disappointment from some stakeholders about the level of detail in the representation of their problem. They suggest the reason for this is that their stakeholders were not comfortable with simplification even though some were aware of the need for it within simulation. One other possibility (in our opinion) is that the pre-model coding (one stage) was not enough for the modelling team and the stakeholder team to gain a relationship of trust. Den Hengst et al (2007) also note that during their equivalent to our experimentation stage (exploring alternatives) the CEO questioned the validity of the results, even though two data experts deemed them to be sound. However in a later stage the CEO expresses trust in the model and the results, suggesting that he needed time to get 'on board'. PartiSim's extra premodel coding stages (discussed earlier in the overview of the PartiSim experimentation and implementation stages) may have an impact on the post model coding stages and particularly on 
validation (Monks et al 2014; 2016). In a similar vein, a GMB study claims that the strongest learning effect comes from being actively involved in formulating mental models rather than from passively reading or listening (Fokkinga et al 2009). Of course there are not enough case studies of either approach to gain a better insight into the effect of pre-model coding facilitation on post-model coding facilitation. Also the difference here could be attributed to cultural issues relating to either industry (Kotiadis and Mingers, 2006).

One key similarity that Den Hengst et al (2007) have with PartiSim's post-model coding facilitation is the implementation stage or as they refer to it: choosing a direction. Clearly both approaches value the notion of a separate and focussed workshop on moving scenarios towards action. Similarly to PartiSim, their chosen scenario was not necessarily the optimum one but one that met the needs of the group. Both approaches have at their core a divergence (e.g. brainstorming) and convergence (e.g. narrowing the selection) principle, which den Hengst et al (2007) detail throughout their case study description.

Considering now the use of tools during the post-model coding stages, neither SimLean (Robinson et al 2014) nor den Hengst et al (2007) put forward facilitation tools to meet specific workshop activities. PartiSim's post-model coding tools, like GSS used by Hengst et al (2007), are aimed at supporting the above mentioned patterns of collaboration that will ultimately lead to each workshop's output. From our experience, using the tools helped the stakeholders to engage in the workshop activities and to alternate between developing divergence (e.g. in Table 1: Debating the solution space tool, Barriers to Change tool) and/or convergence (e.g. in Table 1: feasibility and risks scale Tool, Rating the Performance Measures tool) during the workshop. Divergence is concerned with opening out the issue, and convergence with arriving at agreeable actions (Morton et al 2003; 2007). However these do not always offer anonymity or parallel input because that would require equipment and/or software for each participating member, which may not be available. The idea in PartiSim is that tools should be supported by one laptop operated by a member of the modelling team. However, future case studies may find these tools unnecessary or lead to the development of new ones.

Some preliminary conclusions from the above comparisons are that facilitated DES case studies demonstrate similarities and differences with respect to the stages followed and the activities within a workshop. The comparison has also revealed that the context is not necessarily responsible for similarities or differences in facilitated DES. However in all three case studies we find evidence of participation and acceptance of the model and its findings ranging from immediate to gradual. 


\subsection{Facilitated experimentation and implementation in other modelling approaches}

We now look at experimentation and implementation in other facilitated modelling approaches, beyond simulation. These consist of GMB, MCDA and SSM. These methodologies are deployed through facilitated workshops (Franco and Montibeller 2010) and lend themselves to the post-model coding stages discussed in this paper. SSM does not have tools to support experimentation with its model but the methodology guides towards feasible and desirable solutions and its practice is much more explicit about recording action. Hence we adopted and adapted SSM common practice to design the Action and Communication Plan Tool (table 1). However facilitated SSM may benefit from the idea of standardising the recording of action and putting forward a tool such as PartiSim's. Indeed SSM has many tools (e.g CATWOE) that might also benefit from manuals or scripts focussed on workshop interactions rather than course text books that are more general in their descriptions.

We now consider Multi-Criteria Decision Analysis (MCDA) and facilitated decision analysis. Facilitated decision analysis (Franco and Montibeller 2010) uses a set of methods such as MCDA to model decisions that involve multiple objectives and/or uncertainty of outcomes (Belton and Stewart, 2002; Montibeller and Franco 2011). This is relevant to the later PartiSim stages and particularly the experimentation stage of PartiSim which involves considering different options (scenarios) and outcomes. As explained earlier in sections 3.1 and 4.3 , in PartiSim it is possible to use existing MCDA computer tools such as VISA software (http://www.visadecisions.com) to explore scenarios and their results. The activity is guided by the Rating the Performance Measures Tool and its manual. However the deployment of MCDA is much more limited in PartiSim because it cannot be guaranteed that the criteria chosen by the group to judge the simulation outputs are independent which are required in order to develop independent value functions (Montibeller and Franco 2007. Hence we use MCDA at an exploratory level to get an understanding of the performance of scenarios. Franco and Montibeller (2010) note that methodologies such as Decision Analysis require a stricter specification of variables than qualitative modelling. The same is noted in Brito et al 2012. One could infer from this that a more complete deployment could lengthen the workshop without necessarily adding value to the activities scheduled.

When comparing other facilitated modelling approaches, such as the established GMB with the emerging facilitated DES approaches and in particular PartiSim the opportunities for cross fertilisation are unclear. One question that could be asked is what aspects can be adopted or adapted from GMB practice and what aspects are unique to their respective approach to simulation of SD and DES. With relevance to experimentation, the GMB scripts refer to the review of the progress made at previous meetings as well as scripts designed to facilitate experimentation with a formal simulation model to 
discover options for policy development (Hovmand et al 2012, Vennix 1996; Andersen and Richardson 1997). Considering the overall purpose of the scripts they seem to have similar aims. Similarly the analysis of scenarios and results require quantitative analysis that is not feasible to undertake in workshops with the stakeholders (Vennix 1996). However, as discussed in the background section DES and SD provide different model representations (structures) of the system and also take a different modelling approach, which means that the specific activities involved with model validation and experimentation differ in nature.

A more recent attempt to formalise GMB scripts (Andersen and Richardson 1997; Hovmand et al 2012) is Scriptapedia (Scriptapedia, 2012), an online handbook developed to provide a platform for expert GMB modellers to share their practices with other SD modellers. This handbook is open to expert GMB modellers to add their contributions. Scriptapedia is organised around themes and is more flexible for modellers to choose amongst different available scripts for use in the same modelling session, whereas PartiSim is organised around the modelling stages followed in an intervention, with the view to guiding the modeller during a modelling project. Both address the needs of their respective audience. While Scriptapedia is the result of efforts made to collate existing GMB practice by different expert GMB modellers so far, PartiSim was developed by one team of researchers (the authors), with the view to providing guidance and tools to support the modelling and facilitation process. The final PartiSim process and tools were tested and then amended based on our experience of using them in practice. Furthermore, it should be noted that facilitated DES is in its early stages, and PartiSim is the first approach that, apart from defining the process followed, it includes tools and manuals to guide the modelling process. For this reason there is only one alternative tool available to use in each stage. With time we hope that more tools will be available to use in different stages as researchers or practitioners modify or adapt existing tools or even propose different ones.

Considering more specifically the GMB scripts on Scriptapedia, we notice that most of the scripts refer to developing causal loop diagrams or process mapping which are either relevant to conceptual modelling (pre-model coding) or not fully transferrable to DES modelling due to different formal models developed in each approach. There are however other scripts, such as team working or action ideas scripts (Scriptapedia, 2012) that could be adapted for use in facilitated experimentation and/or implementation DES. At the same time the PartiSim implementation tools and scripts could be also adapted for use in GMB interventions. In time we expect that more ground for cross-fertilisation of ideas as PartiSim and general facilitated DES practice evolve, as well as Scriptaepedia. 


\subsection{Reflecting on facilitated versus expert mode experimentation and implementation in DES}

We now contrast a facilitated mode of practice in DES to the expert mode, focusing particularly on the post-model coding process, with the view to identifying the elements that facilitation brings to DES modelling. One assumption in expert mode relating to the experimentation stage or OR modelling in general is that clients want optimal solutions (Franco and Montibeller 2010). In our facilitated workshops our clients chose satisficing solutions over optimal ones which is in line with other facilitated OR approaches (Franco and Montibeller 2010). Indeed during the implementation workshop described, the stakeholders explored the feasibility of the preferred scenario rather than simply focussing on the improved performance measures. The experimentation phase in expert mode DES as explained in the background section is much more focussed on statistical aspects (Robinson 2014), which cannot be undertaken in workshops as they are deemed to be too technical (for the stakeholders to engage with) and also time consuming. Instead, interactive experimentation can be undertaken during the workshop, where stakeholders can see the outcomes of changes in the model as a result of changes introduced in the input variables. However in some cases, and it was so in our case, implementing certain scenarios may require further modelling which may not be possible to be undertaken in the workshop, which can limit the extent of experimentation to some predefined scenarios. The modelling team can complete the new scenarios outside of the workshop and share the results with the stakeholders after the workshop or at the next workshop. One might argue that this stage is not yet fully facilitated because full exploration of the solution space does not take place in the workshop. This can be overcome if the models are built with a flexible interface wich allows for input parameters to be entered to allow for experimentation at different levels of the input variables. However this requires for the modeller to have identified in advance, prior to the workshop the parameters or variables that can be modified with the scenarios to be tested. This may not always be possible and it depends on the accessibility and amount of interactions with the stakeholder team outside of the workshops. Hence it is not expected that all possible scenarios will have been explored within the experimentation workshop.

An expert mode DES view related to the implementation stage is that implementation of scientificallybased analysis is straightforward yet we have evidence in the literature to the contrary with many studies reporting a lack of implementation of the findings (Brailsford and Vissers 2010; Fone et al 2003; Young et al 2009). On the other hand an assumption of a facilitated mode is that participation increases commitment for implementation (Franco and Montibeller (2010). In the PartSim approach which we have followed, stakeholders attend a series of workshops (four) to ensure that by the end of the study, they are able to take ownership of the model and its findings because of their involvement. Furthermore, in the implementation workshop stakeholders were put through a process to move the 
focus away from the simulation model towards identifying an action trail for change. Separating out this workshop, amongst other things, demonstrates to the stakeholders the importance placed on implementation. All in all, from our experience of PartiSim, the facilitated aspect of modelling has provided a forum where model results are discussed between the analyst and stakeholder team and furthermore subsequent actions to be taken are co-produced, with the latter taking ownership.

\subsection{Future work}

In line with our contribution we initially propose that more facilitated DES case studies are reported that explain the activities followed within a workshop. We propose that workshop interactions are analysed in more detail so that we can learn from these experiences. Specific to workshops on experimentation, further research could focus on understanding how groups identify what scenarios are taken forward. Do groups choose the optimum scenario or the most desirable one? Our case study and den Hengst et al (2007) select the scenario to be taken forward based on what is considered by the group to be desirable rather than optimum. In den Hengst et al (2007), desirability was a case of low risk and in our case study it was a case of realistic implementation of resources. The implications of this, could be that analytical methods commonly used in traditional (expert) mode DES during experimentation should not guide the process of generating a solution space in facilitated DES. Another issue relating to experimentation that needs further research is whether existing simulation software is amenable to facilitated DES. Both this case study and Robinson et al (2014) use SIMUL8, with no reported problems, yet den Hengst et al (2007) who built a bigger scale model use Automod suggest it was too reliant on programming.

Additionally the facilitated DES community would benefit from a debate about the meaning of implementation for facilitated DES that will ultimately lead to agreement on a definition. We also propose exploring learning in facilitated DES as it is said to occur gradually during the intervention and the subjects themselves may not be aware of it happening as it changes the system of beliefs and attitudes, used to make judgements (Nisbett and Wilson 1977; Ajzen 1991; Rouwette 2011). Further research is currently being undertaken analysing our recorded workshop materials (from the current and subsequent interventions) to identify whether divergent (e.g. facilitator helps participants think about their objectives and develop creative and feasible solutions) and convergent (e.g. facilitator helps participants' converge best ideas into options and then to action plan) (Kaner 2007; Franco and Montibeller 2010) thinking processes take place and/or the presence of human emotion and distress (Taket 2002) in the workshops.

We also propose exploring the idea of Pick and Mix. This means combining tools or a workshop process from one line of research e.g. PartiSim with other lines of research even outside the 
healthcare context. For example can the post-model coding approach in PartiSim be used with a different pre-model coding approach? Similarly we encourage the exploration and development of alternative facilitated DES tools that can further improve stakeholder engagement and the process followed to achieve workshop outputs. GMB practice can be explored more to identify ways of applying in facilitated DES and particulary for the implementation stage. Also cross methodological discussions on facilitated research might also consider the extent of the information detailed in a script or manual and consider the level of detail needed to advice facilitators in undertaking facilitated activities. Furthermore, the idea of utilising simulation models beyond the implementation workshop, in the form of role play sessions/workshops, for training and learning purposes for example could be explored. Existing theory from serious gaming (Daalen et al 2014, Platts 1994) and SD microworlds (Vennix 1996, Morecroft 1989) can be utilised to inform such extensions. Franco and Montibeller (2010) also suggest a generalisation of best model-based facilitation practices.

The experimentation stage in PartiSim would benefit from being developed further so it is not limited by the time required to alter the computer model during workshops. This could be aided through further advances of the model coding stage (Proudlove et al 2017). With regard to the same stage, facilitated DES modelling teams could benefit from a greater involvement of an MCDA expert to enable a better combination of facilitated DES practice with MCDA and overcome issues around the flexibility of the modelling rules being deployed (Franco and Montibeller 2010). Other approaches in facilitated decision analysis (Franco and Montibeller 2010) could also be explored for the post-model coding stages in facilitated DES. Indeed more examples are needed between PSMs and facilitated DES to establish what advantages each PSM can bring to this mode of practice.

With respect to the PartiSim process, we reckon that it needs to be repeated several times to make any further claims about its benefits. Also future research could consider if it is as useful in other contexts beyond healthcare. Ideally this should be done by analysts other than the original developers.

\section{Conclusion}

The paper put forward a real case to describe the post-model coding process and tools to attain specific outputs for facilitated group experimentation and decision making when using the PartiSim framework. This is another step towards understanding facilitated DES. To our knowledge so far of the existing facilitated practice, PartiSim is the only DES approach that has developed tools aimed at supporting the specific activities in workshops. The paper puts forward an extensive line of proposed research in a bid to encourage other DES groups to enter this line of research and to encourage those already publishing in this line to engage in a dialogue over differences and commonalities. 


\section{Acknowledgments}

This study was supported by the UK Engineering and Physical Sciences Research Council (EPSRC) grant EP/E045871/1. Kathy Kotiadis also acknowledges the support of the Daphne Jackson Trust and the University of Kent in the dissemination of this study. Antuela Tako acknowledges the support provided by Loughborough University in expanding and disseminating the work on the PartiSim project. The authors are grateful to the anonymous referees for their valuable suggestions and direction that helped us improve this paper.

\section{References}

Adamides, E.D., Karacapilidis, N., 2006. A knowledge centred framework for collaborative business process modelling. Business Process Management Journal 12 (5), 557-575.

Andersen, D. F., \& Richardson, G. (1997). Scripts for group model building. System Dynamics Review, 13(2), 107-129

Ajzen, I. (1991). "The theory of planned behaviour." Organisational Behaviour and Human Decision Processes 50: 179-211.

Barjis, J., 2011. CPI Modeling: Collaborative, Participative, Interactive Modeling. In: Jain, S., Creasey, R.R., Himmelspach, J., White, K.P., Fu, M. (Eds.), Proceedings of the 2011 Winter Simulation Conference. IEEE, Piscataway, NJ, pp. 3099-3108.

Baril C, Gascon V, Miller J, Côté N, (2016). Use of a discrete-event simulation in a Kaizen event: A case study in healthcare, European Journal of Operational Research, 249(1), 16: 327-339

Belton, V. and T. J. Stewart (2002). Multiple criteria decision analysis: an integrated approach. Dordrecht, Kluwer.

Brailsford, S.C., Bolt T., Connell C., Klein, J.H. and Patel, B. (2009) Stakeholder Engagement in Healthcare Simulation in: M. D. Rossetti, R. R. Hill, B. Johansson, A. Dunkin and R. G. Ingalls, (eds.) Proceedings of the 2009 Winter Simulation Conference, Austin, Texas, USA, 13-16 December 2009, p.1840-1849.

Briggs RO, de Vreede GJ and Nunamaker Jr JF (2003). Collaboration engineering with thinklets to pursue sustained success with group support systems. J Mngt Inform Syst 19: 31-64.

Briggs RO, Kolfschoten GL, de Vreede GJ and Dean DL (2006). Defining key concepts for collaboration engineering. In: Garcia I and Trejo R (eds). Proceedings of the 12th Americas Conference on Information Systems, Acapulco, Mexico, pp 121-128.

Brito, T.B., dos Santos Silva, R.C. Trevisan, E.F.C. and Botter R.C. (2012). Discrete Event Simulation Combined with Multiple Criteria Decision Analysis as a Decision Support Methodology in Complex Logistics Systems, Discrete Event Simulations - Development and Applications, Dr. Eldin Wee Chuan Lim (Ed.), InTech, DOI: 10.5772/50107.

Brooks RJ and Tobias AM (1996). Choosing the best model: Level of detail, complexity and model performance. Math Comput Model. 24(4). 1-14.

Checkland, P.B., 1981. Systems Thinking, Systems Practice. Wiley, Chichester, UK.

Checkland P.B., (1999). Systems thinking systems practice. Wiley. Chichester. UK.

Churchman, C.W., Schainblatt, A.H., 1965. The researcher and the manager: a dialectic of implementation. Management Science 11 (4), B69-B87.

Davison RM and Briggs RO (2000). GSS for presentation support. Commun ACM 43: 91-97.

den Hengst, M., de Vreede, G.J., Maghnouji, R., 2007. Using soft OR principles for collaborative simulation: a case study in the Dutch airline industry. Journal of the Operational Research Society 58 (5), 669-682.

Department Of Health (2004). The NHS Improvement Plan: Putting People at the Heart of Public Services. Publication. SERIES: Cm 6268 ISBN 0-10-162682-7. TSO. London. UK

Eldabi T, Paul RJ and Young T (2007). Simulation modelling in healthcare: reviewing legacies and investigating futures, Journal of the Operational Research Society. 58. 262-270.

Fjermestad J and Hiltz SR (1998-1999). An assessment of group support systems experimental research: Methodology and results. J Mngt Inform Syst 15: 7-149. 
Fokkinga, B. L. A., Bleijenbergh, I. L., \& Vennix, J. A. M. (2009). Group model building evaluation in single cases: a method to assess changes in mental models. In: Proceedings of the 27th International Conference of the System Dynamics Society, New Mexico, USA.

Fone D, Hollinghurst S, Temple M, Round A, Lester N, Weightman A, Roberts K, Coyle E, Bevan G, and Palmer $P$ (2003). Systematic review of the use and value of computer simulation modelling in population health and health care delivery. Journal of Public Health 25(4): 325-335.

Franco, L. and G. Montibeller (2010). "Facilitated modelling in operational research." European Journal of Operational Research 205: 489-500.

Friend, J. K. and Hickling, A. (1987) Planning Under Pressure, Chichester, England : John Wiley and Sons.

Gunal M and Pidd M (2005) Simulation modelling for performance measurement in healthcare, In: M.E Kuhl, N.M. Steiger, F.B. Armstrong and J.A Joines (eds) Proceedings of the 2005 Winter Simulation Conference, Orlando, FL, USA, December 4-7, 2005. ACM: 2663-2667.

Henriksen JO (1988). One system, several perspectives, many models. In Proceedings of the 1988 Winter Simulation Conference. M. Abrams, P. Haigh, J Comfort. IEEE. Piscataway. NJ.

Huxham C (1991) Facilitating collaboration: issues in multiorganisational group decision support in voluntary, informal collaborative settings. Journal of the Operational Research Society 42:1037-1045.

Hovmand, P. S., Andersen, D. F., Rouwette, E. A. J. A., Richardson, G. P., Rux, K., \& Calhoun, A. (2012). Group model-building 'scripts' as a collaborative planning tool. Systems Research and Behavioral Science, 29(2), 179-193.

Jun JB, Jacobson SH, and Swisher JR (1999). Application of discrete-event simulation in health care clinics: A survey. Journal of the Operational Research Society 50(2): 109-123.

Kaner S(2007). Facilitator's Guide to Particpatory Decision Making. San Francisco, CA, Jossey-Bass.

Kotiadis, K. and J. Mingers (2006). "Combining PSMs with hard OR methods: the philosophical and practical challenges." Journal of the Operational Research Society 57(7): 856-867.

Kotiadis K and A.A. Tako (2010) PartiSim User Guide to Facilitation:Version 1. (https://www.researchgate.net/publication/284030194_final_PARTISIM). DOI: 10.13140/RG.2.1.3659.1201

Kotiadis, K., Tako, A.A. and Vasilakis, C. (2014) A Participative and Facilitative Conceptual Modelling Framework for Discrete Event Simulation Studies in Healthcare, Journal of the Operational Research Society, 65(2): 197-213.

Law, A.M., 2007. Simulation Modeling and Analysis, fourth ed. McGraw-Hill, New York.

Lowery JC (1994). Barriers to implementing simulation in health care. In Proceedings of the 1994 Winter Simulation Conference, Tew J.D, Mannivannan S, Sadowski D.A. and Seila A.F. (eds) December 11-14. 1994. Lake Buena Vista, FL, USA. ACM. 868-875.

Monks, T, Robinson, S and Kotiadis, K (2014) Learning from discrete-event simulation: exploring the high involvement hypothesis. European Journal of Operational Research, 235, (1), 195-205.

Monks, T, Robinson, S and Kotiadis, K, (2016) Can involving clients in simulation studies help them solve their future problems? A transfer of learning experiment. European Journal of Operational Research, 249, (3), 2016, 919-930, http://dx.doi.org/10.1016/j.ejor.2015.08.037.

Montibeller, G and Franco, LA (2007) Decision and Risk Analysis for the evaluation of strategic options. In O'Brien, $\mathrm{F}$ and Dyson, R (ed) Supporting strategy: Frameworks, methods and models, pp.251-284.

Montibeller, G. and Franco, L. (2011) Raising the bar: strategic multi-criteria decision analysis J Oper Res Soc (2011) 62: 855-867. https://doi.org/10.1057/jors.2009.178

Morecroft, J (1989). Strategic Microworlds and System Dynamics Modelling, Transactions of the Institute of Measurement and Control, Vol. 114, No. 4, , pp. 180-186. doi:10.1177/014233128901100403.

Morton A, Ackermann, F and Belton V. (2007) Problem structuring without workshops? Experiences with distributed interaction within a PSM process. Journal of the Operational Research Society 58, 547-556. 
Morton A, Ackermann, F and Belton V. (2003) Technology-driven and model-driven approaches to group decision support: focus, research philosophy, and key concepts. European Journal of Information Systems 12, 110-126

Nance 1994 Nance, R. (1994). "The Conical Methodology and the evolution of simulation model development." Annals of Operations Research 53(1): 1-45.

Nisbett, R. E. and T. D. Wilson (1977). "Telling more than we can know: Verbal reports on mental processes." Psychological Review 84(3): 231-259.

Nunamaker Jr JF, Dennis A, Valacich J, Vogel D and George JF (1991). Electronic meeting systems to support group work. Commun ACM 34: 40-61.

Nunamaker Jr JF, Briggs RO, Mittleman DD, Vogel DR and Balthazard PA (1997). Lessons from a dozen years of group support systems research: A discussion of lab and field findings. J Mngt Inform Syst 13: 163-207.

Pessôa LAM, Lins MPE, da Silva ACM, Fiszman R. (2015). Integrating soft and hard operational research to improve surgical centre management at a university hospital, European Journal of Operational Research, 245 (3): 851-861.

Platts KW (1994) Characteristics of methodologies for manufacturing strategy formulation, Computer Integrated Manufacturing, 7(2) 93-99.

Pritsker AAB (1986). Model evolution: A rotary table case history. In Proceedings of the 1986 Winter Simulation Conference. J. Wilson, J. Henriksen And S. Roberts. Eds. IEEE. Piscataway. NJ.

Proudlove, N.C., Bisogno, S. , Onggo, B.S.S., Calabrese, A. and N. Levialdi Ghiron, (2017) Towards fullyfacilitated discrete event simulation modelling: Addressing the model coding stage, European Journal of Operational Research, 263, (2), 2017, 583-595. ISSN 0377-2217, http://dx.doi.org/10.1016/j.ejor.2017.06.002.

Phillips, L. D. and M. C. Phillips (1993). "Faciliated Work Groups: Theory and Practice." Journal of the Operational Research Society 44(6): 533-549.

Robinson S (2014) Simulation:The Practice of Model Development and Use, ( ${ }^{\text {nd }}$ Edition).

Robinson, S. and Pidd, M. (1998). Provider and Customer Expectations of Successful Simulation Projects. Journal of the Operational Research Society, 49 (3), 200-209.

Robinson, S., Radnor, Z.J., Burgess, N., Worthington, C., 2012. SimLean: utilising simulation in the implementation of lean in healthcare. European Journal of Operational Research 219, 188197.

Robinson, S., Worthington, C., Burgess, N. and Radnor, Z.J. (2014). Facilitated modelling with discreteevent simulation: Reality or myth? European Journal of Operational Research, 234 (1): 231240.

Rosenhead, J. and J. Mingers (2001). Rational Analysis for a problematic world revisited. Chichester, Wiley.

Rouwette E. A. J. A., Vennix J.A.M. and Mullekom T.V. (2002) Group model building effectiveness: A review of assessment studies, System Dynamics Review 18(1): 5-45.

Rouwette, EAJA, Vennix, JAM and Thijssen CM (2000) Group Model Building: A Decision Room Approach, 31(3): 359-379.

Rouwette, E. A. J. A. (2011). "Facilitated modelling in strategy development: measuring the impact on communication, consensus and commitment." Journal of the Operational Research Society 62(5): 879-887.

Sachdeva R, Williams T and Quigley J (2007) Mixing methodologies to enhance the implementation of healthcare operational research, Journal of the Operational Research Society, 58, 159-167.

Schultz, R L, Slevin DP, Pinto JK (1987) Strategy and Tactics in a Process Model of Project Implementation, 17(3): 34-46.

Scriptapedia in Wikibooks. https://en.wikibooks.org/wiki/Scriptapedia, accessed 21/07/2017.

Taket, A R (2002). "Facilitation: some contributions to theorising the practice of operational research." Journal of the Operational Research Society 53(2): 126-136.

Taket AR and White LA (2000) Partnerships and Participation: Decision making in the Multiagency Setting. Wiley: Chichester. 
Tako AA, Kotiadis K, Vasilakis C, (2010) 'A Participative modelling framework for developing conceptual models in healthcare simulation studies', Proceedings of the 2010 Winter Simulation Conference, B. Johansson, S. Jain, J. Montoya-Torres, J. Hugan, and E. Yücesan, eds. IEEE, Baltimore: Maryland USA. pp.500-512, ISBN: 978-1-4244-9864-2 DOI 10.1109/WSC.2010.5679135

Tako AA and Kotiadis K, (2012a) 'Facilitated conceptual modelling: Practical issues and reflections', Proceedings of the 2012 Winter Simulation Conference. C. Laroque, J. Himmelspach, R. Pasupathy, O. Rose, and A.M. Uhrmacher, eds, Berlin, IEEE, Germany. http://dl.acm.org/citation.cfm?id=2430284

Tako AA and Kotiadis K (2012b), 'Proposing a Participative Modelling Framework for Discrete Event Simulation Studies,' HICSS, 2012 45th Hawaii International Conference on System Sciences, Maui, Hawaii, USA. pp.207-215 ISBN: 978-0-7695-4525-7. DOI: 10.1109/HICSS.2012.489

Tako A.A., Kotiadis K, Vasilakis C, Miras A and le Roux CW. (2014) Improving patient waiting times: a simulation study of an obesity care service study. BMJ Quality and Safety. 23, pp. 373-381.

Tako A A and Kotiadis K (2015) PartiSim: A Framework for participative simulation modelling. European Journal of Operational Research, 244 (2): 555-564. DOI: 10.1016/j.ejor.2015.01.046.

Tako AA and Robinson S (2015) Is Simulation in Health Different, Journal of the Operational Research Society, 66: 602-614. DOI:10.1057/jors.2014.25.

Tyran CK, Dennis AR, Vogel DR and Nunamaker Jr JF (1992). The application of electronic meeting technology to support strategic management. Mngt Inform Syst Quart 16: 313-334.

van Daalen, CE, Schaffernicht, M, Mayer, I, (2014) System Dynamics and Serious Games, In: Proceedings of the $32^{\text {nd }}$ International Conference of the System Dynamics Society, Delft, The Netherlands, July 20-24, 1-26.

van Der Zee DJ( 2007). Developing participative simulation models: Framing decomposition principles for joint understanding. Journal of Simulation. 1, 187-202.

van Der Zee DJ (2011). Developing participative simulation models: Framing decomposition principles for joint understanding. In Conceptual modelling for discrete event simulation, S. Robinson, R. Brooks, K. Kotiadis, and DJ. Van Der Zee, Eds. CRC Press. Boca Raton, FL. 103-132.

Van Der Zee DJ and van Der Vorst JGAJ (2005). A modelling framework for supply chain simu-lations: Opportunities for improved decision making. Decis Sci. 36. 65-95.

Vennix J (1996). Group Model Building: Facilitating Team Learning Using System Dynamics. Wiley: London.

Vennix JAM (1999) Group model-building:tackling messy problems. Systems Dynamics Review. 15(4): 379-401.

White LA and Taket AR (1994) The death of the expert. Journal of the Operational Research Society. 45: 733-748

Willemain TR (1994). Insights of modelling from a dozen experts. Opns Res. 42. 413-222.

Wilson, J.C.T. (1981). Implementation of computer simulation projects in health care. J Opl Res Soc 32(9): 162-164.

Young, T., Eatock, J., Jahangirian, M., Naseer, A. and Lilford, R.J. (2009) Three Critical Challenges for Modeling and Simulation in Healthcare in: M. D. Rossetti, R. R. Hill, B. Johansson, A. Dunkin and R. G. Ingalls, (eds.) Proceedings of the 2009 Winter Simulation Conference, Austin, Texas, USA, 13-16 December 2009, p. 1823-1830. 